\title{
Investigating the Application of Systems Engineering to the Design of Manufacturing Systems
}

\author{
Pascal Hofmann \\ Mechanical Engineering Division \\ Technical Academy Esslingen \\ Stuttgart, Germany
}

\author{
Cecilia Haskins \\ Dept. Production and Quality Engineering \\ NTNU \\ Trondheim, Norway \\ cecilia.haskins@ntnu.no
}

\begin{abstract}
The increasing complexity of manufacturing systems in highly competitive environments motivates the need for refinement of the design of manufacturing systems. The application of systems engineering is still undeveloped in some industries, but the potential benefits are substantial. However, there exists a chasm between the theory and practice of systems engineering applied to the design of manufacturing systems and existing lack of information sharing among organizations to enable right first time practices. To close this gap, the authors suggest systems engineering methods for supporting and enabling more effective and efficient design of manufacturing systems.
\end{abstract}

Keywords- Manufacturing system design, product quality, responsiveness, stakeholders, systems engineering

\section{INTRODUCTION}

Manufacturing Systems (MS) are among the most complex man-made systems, but sit in the shadows cast by the spotlight on the products they produce. Modern MS are based on advanced technology and composed of interrelated mechanical, electronic and software components. The performance of MS in an operational environment depends on technological choices and the design of effective and efficient manufacturing solutions [1]. The design and implementation of next generation manufacturing requires 1) research into new methodologies to support the systematic implementation of best practices in industry; 2) new models, problem solving and modelling techniques for the efficient and effective design, planning, implementation and execution of MS; and 3) new information systems to support integrated product and production with a life cycle approach [2, 3, 4]. Case studies by Li et al. [5] show that using systems engineering (SE) in production systems provides a science-based method for continuous improvement. SE as a discipline emerged from the need to cope with complexity in man-made systems. As MS are becoming increasingly complex, the application of SE offers substantial benefits, as Haskins and Alfnes [6] point out. Despite an early mention of manufacturing systems engineering (MSE) by Buchan and Preston in 1992 [7], many companies think they are doing fine and too busy to do anything differently. This is especially true if company success is based on technology, and the literature on factory design is primarily focused on computer-based support for production processes [8].

\section{BACKGROUND}

MS represent a large investment and the potential to impact several product generations, which means the focus must be on designing and building in quality from the start. Hofmann and Powell [9] point out that a structured approach in the design process can reduce the total systems design life cycle and the amount of redesign. Manufacturing companies that shift the design tasks to an earlier phase of the development process can enhance the overall development performance [10,11]. Right first time practices seem self-evident because no one begins a design expecting to redesign it later. However, companies routinely tolerate change orders, maybe because they always have, then they call them "revisions" or even "updates." A right-first-time mindset is lacking [12].

All enterprises are experiencing a global transformation that is speeding up the rate of business activity. Companies no longer can afford to use months to make design decisions. To create competitive advantage in fluctuating market environments, enterprises must design MS that not only produce high-quality products at low cost, but also allow for rapid response to market changes and consumer needs [13]. Responsiveness emerges as a key competitive advantage. However, there exists a major disadvantage in traditional design processes - there is a substantial lack of interaction with stakeholders of the enterprise [14].

Manufacturing enterprises face many challenges related to quality, responsiveness and the ability to innovate. The design of MS and the design of products are tightly interrelated. Research and practice exists to design both MS and products but independently. $\mathrm{Li}$ and $\mathrm{Li}$ [5] argue for opening a new direction of research in MSE. They highlight the impact of the quality of the MS on product design; namely, a manufacturing enterprise cannot be responsible for guaranteeing good quality for a poorly designed product. Equally, a well-designed product will be impacted by a poorly designed MS. Ultimately, an enterprise that understands the significance of the interface between MS and product design will enable higher quality products as well as cost-efficient production [15]. 
Koren [16, 17] emphasizes rapidly changing customer needs as the most prominent driving factor for manufacturing enterprises. Bollinger [18] points out that the product design process must be quick and integrated with the manufacturing solutions that will produce it. To cope with those challenges, it is necessary to increase the design process efficiency and effectiveness in a connected and cooperative way for both product design and production design. 50-70\% of all new product introductions fail, due to changing customer demands and competitive offerings [16]. A survey of 650 world's leading manufacturers conducted by Deloitte's Global Benchmark Study program [19] exposed that supporting product innovation is one of their least important priorities. Koren [16: 16] argues: "If new, innovative products are the main source of a company's growth, why is the support of innovation so low, and why do new products fail so frequently?" Deloitte's survey demonstrates that manufacturing enterprises were unable to bring new products to market successfully mainly due to insufficient information on customer demands.

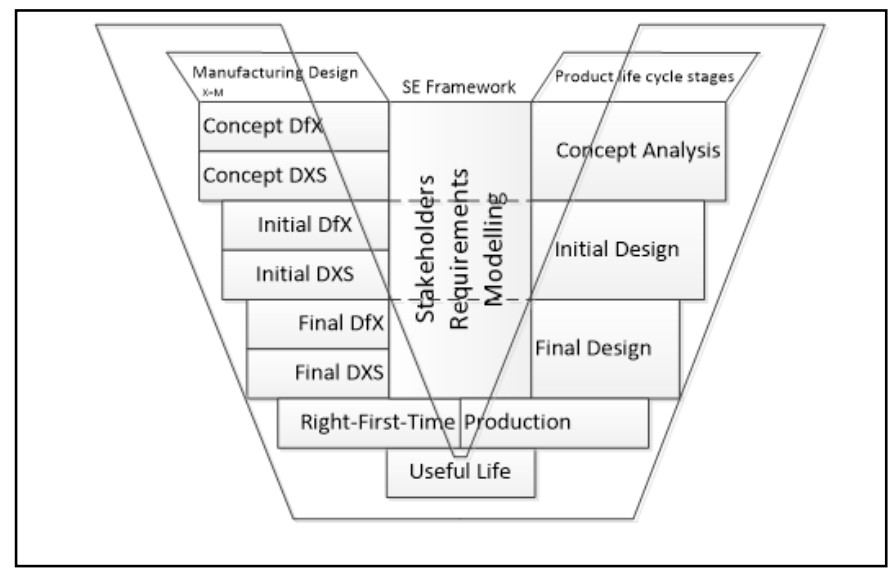

Fig. 1 - V-MSP model

\section{ADDRESSING THE CHALLENGES}

The bulk of literature on SE focuses on applications of the discipline to the product development domain [12]. Fig. 1 illustrates the interdependencies that exist between the product lifecycle stages and the manufacturing design using a modified V-model $[20,21]$ and named the "V-MSP model" (V for Vmodel, $\mathrm{M}$ for manufacturing design, $\mathrm{S}$ for SE framework, and $\mathrm{P}$ for product life cycle). The figure shows the similarities of both product and manufacturing (X) activities from the conceptual design to initial design, final design to production, and including useful life. Often products are designed and then handed over to others, but many product innovations fail by virtue of the inability to manufacture them. A systematic business strategy supported by SE enables coordination between the two design domains. Concurrent engineering practices have evolved to address the problems caused by design silos and help avoid the vicious cycle of redesigns by integrating product and production designs, i.e. a collaboration of design for manufacturing (DfM) and design of manufacturing systems (DMS), by taking a life cycle perspective. The focus needs to be on the negotiations and relationships between product and manufacturing stakeholder requirements, supported in the middle of Fig. 1 by the SE framework; stakeholders, requirements, and modeling. It is reported that some companies resist DfM as too time consuming [12].

\section{A REVIEW OF DMS METHODS}

While many manufacturing companies have their own design procedures, often established through custom and practice, there are relatively few comprehensive examples published in sufficient detail to be of value [2]. A thorough review of the literature uncovered seven candidate methods that support MS design and these are summarized here and compared in Table 1.

(1) An approach called 'Lucas' takes a MS perspective based on the redesign of business organizations [22, 23]. This methodology is well established and has been extensively applied and tested since the 1970s [24, 25, 26]. The Lucas method defines the ideal design of MS with two core processes: 1. Manufacturing operations and 2. product introduction processes [22]. Parnaby [25] introduces five stages of MS design in relation to the Lucas approach: 1. 'Market analysis'; 2. 'Business process analysis' (including process mapping); 3. 'Steady state design' (including ensuring that the system is balanced and synchronized); 4. 'Dynamic design'; and 5. 'Information and control design and system information'.

(2) Watson [27] criticized the process movement and designed what he called the principles of business SE. All processes consist of sub-processes that deliver a common purpose [27] by understanding and satisfying customer needs with effectively operating processes that meet the need [26]. The wealth of methodologies available, whether they relate to systems thinking or business process re-engineering (BPR), were summarized by Watson [27] as UDSO/ BPR method [2]: 1. 'Understanding' (problem definition, systems boundaries and performance metrics); 2. 'Document' (process mapping); 3. 'Simplify' (eliminating all kinds of waste [time, information flow, material etc.]); 4. 'Optimize' (e.g. verify and validate).

(3) Among several authors that emphasized the need for better integration of manufacturing design disciplines (Hitomi 1997, Meller and Gau 1996, Wu 1994), Wu suggested the most comprehensive method (Cochran et al. 2002). A design and evaluation methodology is composed of five activities: 1 . 'Analysis of situation'; 2. 'Setting objectives'; 3. 'Conceptual modelling'; 4. 'Detailed design'; 5. 'Evaluation and decision'.

(4) 'Design rules for analyzing manufacturing activities' (DRAMA) and 'Decision rules for analyzing manufacturing activities' (DRAMA II) [28] both aim to avoid prescriptive solutions but encourage the designer to make informed choices through a series of 'design option guides' from strategic to operational issues [29]. They recommend the following activities: 1. 'Strategic' (based on decision process effects in relation to organizational and operational implications as well as marketing and manufacturing strategies); 2. 'Organizational' (analyzing of strategic factors); 3. 'Operational' (physical design, implementation and operation of the new system) [30]. 
(5) 'Main levels and activities in MS design process' were summarized in the work of AlGeddawy and ElMaraghy [31]. These activities are generally performed in any MS design process and were categorized into four levels: system, factory, machine, and product levels. They further defined the systems design level as: 1. 'Stating objectives'; 2. 'Defining subsystems'; 3. 'Mapping between requirements \& actions'; and 4. 'Adopting control strategy'. Systems designs should include functional (what is required) and physical (how it can be done) domains as well as how it is managed and mapped in the process.

(6) Chowdhury [31] suggests the following sequential seven-step process for Design for Six Sigma (DFSS): 1. 'Understand' who the customers are; 2. 'Capture and analyze' the voice of the customer; 3 . 'Translate the voice of the customer' into performance requirements; 4 . 'Choose the best' design concept to meet the performance requirements; 5 . 'Translate the performance requirements' into product/ service design parameters; 6. 'Translate the product parameters' into manufacturing conditions (this step does not apply to a service); 7. 'Determine activities' required maintaining manufacturing conditions or service process parameters. The DFSS method was originally designed to help remove defects in company processes and is highly reliant on statistical methods [32].

((7)) Cochran et al. [33] recognize that several tools to design MS exist, but that many do not separate objectives from means, so it is difficult to understand the interactions among different design objectives and solutions. They recommend MS Design Decomposition (MSDD), which is intended to help MS designers but is operationally-based and therefore not possible to compare in Table 1 .

To conclude, there appears to be no universal theory describing exactly how all of the design activities do or should come together for a structured design approach in the MS domain for supporting the interrelation with the product design. Most design methods are just theories that have not been evaluated, may be unnecessarily complicated, or do not provide a useful set of guidelines [30, 34].

\section{DISCUSSION}

A literature review of the MS design domain highlights the gap between the product and the MS design theory and practice. Essential methods to meet increasing competitiveness are generally not covered to enable right-first-time design practices. The authors propose adoption of a set of SE activities listed in Table 1, which summarizes the DMS methods and compares them to the SE activities that shall support the interface between the manufacturing design and product design. Through a careful review of the various DMS methods it was possible to identify similarities and activities that are only partially covered or missing.

As seen in Table 1, none of the earlier methods 1-5 fully cover the essential SE activities. Notably, stakeholder analysis, critical to both responsiveness and innovation are missing in methods 2, 3, and 5. Formulation of a clear problem statement is missing for methods 1 and 4, which also fail to construct measures of effectiveness that capture the results of their stakeholder analysis. Only DFSS, which has its roots in SE from Motorola, covers the full set. In addition, most of the proposed design approaches either do not provide guidelines, or do not meet stakeholder requirements (e.g. to avoid redesigns). Guidelines with a systematic and practical approach to design MS are needed to fill the gaps.

\section{CONCLUSION}

The authors identified through a literature review that manufacturing enterprises need to move toward a more cooperative-driven environment and highlight the impact of the quality of the MS on product design: An enterprise that understands the significance of the interface between MS and product design will enable higher quality products as well as cost-efficient production.

The V-MSP Model illustrates the interdependencies that exist between the product lifecycle stages and the manufacturing design and how these align with three SE aspects. However, this simplified model would be insufficient in the design of a truly complex MS, for example an automobile factory. The application of the six essential SE methods given in table 1 supports and secures the cooperation, negotiations and relationships between the product requirements and manufacturing design. Application of SE enables bringing innovative and high quality products to the market in a timely manner by decreasing costly redesigns and other forms of rework and contributes to a more sustainable manufacturing environment. The conventional DMS methods when compared to the essential SE activities are found to be incomplete, which suggests the need to increase MSE research to enhance manufacturing competitiveness for the next century.

\section{ACKNOWLEDGMENT}

The authors would like to thank Professors Hans Jørgen Dahl and Gerrit Muller and Dr. Daryl Powell for their support and feedback to an earlier draft of this article.

\section{REFERENCES}

[1] BRUCH, J. 2012. Management of Design Information in the Production System Design Process. Doctoral thesis, Mälardalen University.

[2] MOlinA, A., RODRIGUEZ, C. A., AHUETT, H., CORTÉS, J. A., RAMÍREZ, M., JIMÉNEZ, G. \& MARTINEZ, S. 2007. Nextgeneration manufacturing systems: key research issues in developing and integrating reconfigurable and intelligent machines. International Journal of Computer Integrated Manufacturing, 18, 525-536.

[3] BUZACOTT, J. 2013a. The Design of Manufacturing Systems to Cope with Variability. In: SMITH, J. M. \& TAN, B. (eds.) Handbook of Stochastic Models and Analysis of Manufacturing System Operations. Springer New York.

[4] BUZACOTT, J. A. 2013b. Then and now - 50 years of production research. International Journal of Production Research, 51, 6756-6768.

[5] LI, J. \& LI, J. 2013. Integration of manufacturing system design and quality management. IIE Transactions, 45, 555-556.

[6] HASKINS, C. \& ALFNES, E. 2010. Systems Engineering - A promising approach for Design of Manufacturing Systems. SINTEF A16209 Report.

[7] BUCHANAN, D. \& PRESTON, D. 1992. Life in the cell: supervision and teamwork in a 'manufacturing systems engineering' environment. Human Resource Management Journal, 2, 55-76. 
[8] CONSTANTINESCU, C. \& WESTKÄMPER, E. 2009. A Reference Model for Factory Engineering and Design. Springer-Verlag Berlin Heidelberg, pp. 1551-1564.

[9] HOFMANN, P. \& POWELL, D. The Combination of Lean Thinking and Systems Thinking in the Design of Manufacturing Systems. International Conference on Industrial Engineering and Engineering Management (IEEM), 2012 Hong Kong. IEEEXplore.

[10] THOMKE, S. \& FUJIMOTO, T. 2000. The effect of "front-loading" problem-solving on product development performance. Journal of Product Innovation Management, 17, 128-142.

[11] KENNEDY, F. A. \& WIDENER, S. K. 2008. A control framework: Insights from evidence on lean accounting. Management Accounting Research, 19, 301-323.

[12] ANDERSON, D. M. 2014. Design for Manufacturability: How to Use Concurrent Engineering to Rapidly Develop Low-Cost, High-Quality Products for Lean Production, CRC Press.

[13] KOREN, Y. \& SHPITALNI, M. 2011. Design of reconfigurable manufacturing systems. Journal of Manufacturing Systems, 29, 130-141.

[14] HOWE, J. 2006. The rise of crowdsourcing. Wired magazine, 14, 1-4.

[15] INMAN, R. R., BLUMENFELD, D. E., HUANG, N., LI, J. \& LI, J. 2013. Survey of recent advances on the interface between production system design and quality. IIE Transactions, 45, 557-574.

[16] KOREN, Y. 2010. The Global Manufacturing Revolution: ProductProcess-Business Integration and Reconfigurable Systems, Hoboken, NJ, USA, Wiley Series in Systems Engineering and Management.

[17] KOREN, Y., HEISEL, U., JOVANE, F., MORIWAKI, T., PRITSCHOW, G., ULSOY, G. \& VAN BRUSSEL, H. 1999. Reconfigurable Manufacturing Systems. CIRP Annals - Manufacturing Technology, 48, 527-540.

[18] BOLLINGER, J., BENSON, D. \& CLOUD, N. 1998. Visionary manufacturing challenges for 2020. National Research Council Report.

[19] DELOITTE 2005. Deloitte's Global Benchmark Study Program. 3rd Report: Mastering Innovation.

[20] ROOK, P. 1986. Controlling software projects. Software Engineering Journal, 1, 7.

[21] FORSBERG, K., MOOZ, H. \& COTTERMAN, H. 1996. Visualizing Project Management, John Wiley \& Sons.
[22] PARNABY, J. 1986. The design of competitive manufacturing systems. International Journal of Technology Management, 1, 3, 385-396.

[23] MASON-JONES, R., BERRY, D. \& NAIM, M. M. 1998. A systems engineering approach to manufacturing systems analysis. Integrated Manufacturing Systems, 9, 350-365.

[24] PARNABY, J. 1979. Concept of a manufacturing system. International Journal of Production Research, 17, 123-135.

[25] PARNABY, J. 1991. Designing effective organizations. International Journal of Technology Management, 6, 1, 15-32.

[26] PARNABY, J. 1994. Business process systems engineering. International Journal of Technology Management, 9, 3, 497-508.

[27] [27] WATSON, G. H. 1994. Business systems engineering: Managing breakthrough changes for productivity and profit, John Wiley \& Sons Inc.

[28] [28] BENNETT, D. J. \& FORRESTER, P. L. 1993. Market-focused production systems: design and implementation, Prentice Hall.

[29] [29] LOVE, D. 1996. The Design of Manufacturing Systems. International Encyclopedia of Business and Management 4, 3154-3174.

[30] [30] WU, B. 1994. Manufacturing systems design and analysis: context and techniques, Springer.

[31] [31] ALGEDDAWY, T. N. \& ELMARAGHY, H. A. 2009. Changeability Effect on Manufacturing Systems Design. In: ELMARAGHY, H. A. (ed.) Changeable and Reconfigurable Manufacturing Systems. Springer London.

[32] [31] CHOWDHURY, S. 2002. Design for Six Sigma: The Revolutionary Process for Achieving Extraordinary Profit. Chicago, IL: Kaplan Publishing.

[33] [32] KWAK, Y. H. \& ANBARI, F. T. 2006. Benefits, obstacles, and future of six sigma approach. Technovation, 26, 708-715.

[34] [33] COCHRAN, D. S., ARINEZ, J. F., DUDA, J. W. \& LINCK, J. 2002. A decomposition approach for manufacturing system design. Journal of Manufacturing Systems, 20, 371-389.

[34] WHITE, K. P. 1998. Systems design engineering. Systems Engineering, $1,285-302$. 
Table 1: DMS comparison

\begin{tabular}{|c|c|c|c|c|c|c|c|c|}
\hline \multirow[t]{2}{*}{ 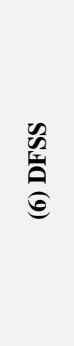 } & \multirow[t]{2}{*}{ 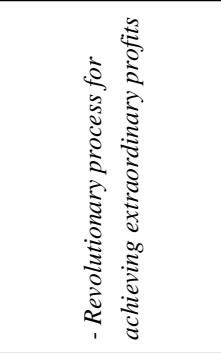 } & \multirow[t]{2}{*}{ 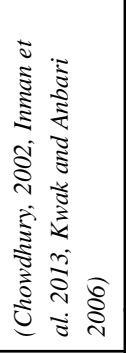 } & 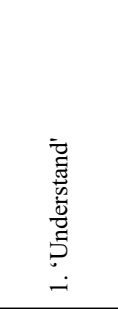 & 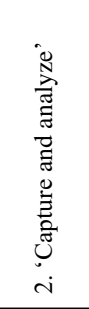 & 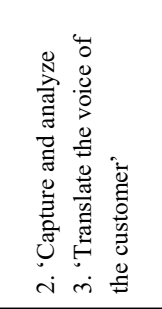 & 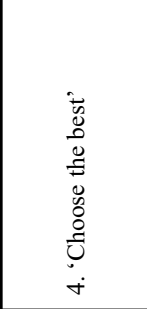 & 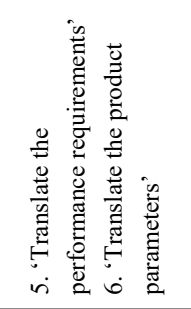 & 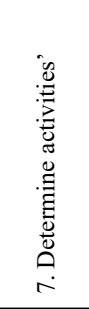 \\
\hline & & & $\odot$ & $\odot$ & $>$ & $\odot$ & $>$ & $\odot$ \\
\hline \multirow[t]{2}{*}{ 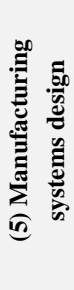 } & \multirow[t]{2}{*}{ 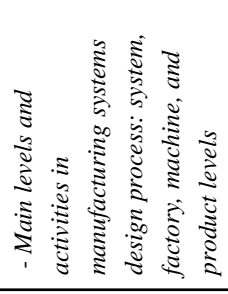 } & \multirow[t]{2}{*}{ 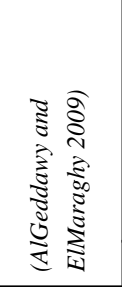 } & 1 & 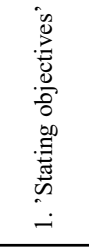 & & 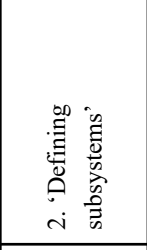 & 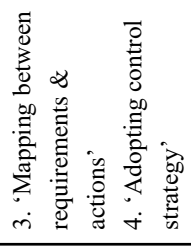 & 1 \\
\hline & & & & $\odot$ & & $>$ & $>$ & \\
\hline \multirow[t]{2}{*}{ 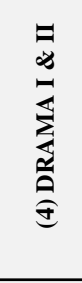 } & \multirow[t]{2}{*}{ 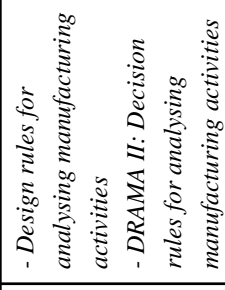 } & \multirow[t]{2}{*}{ 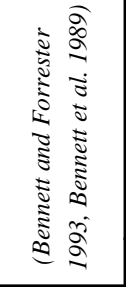 } & 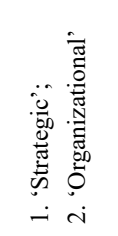 & & & 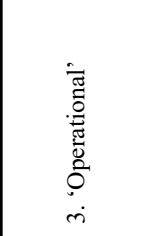 & 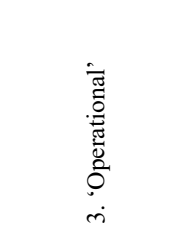 & 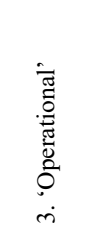 \\
\hline & & & $\odot$ & & & $\odot$ & $\odot$ & $\odot$ \\
\hline \multirow[t]{2}{*}{ 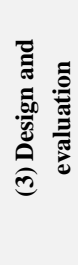 } & \multirow[t]{2}{*}{ 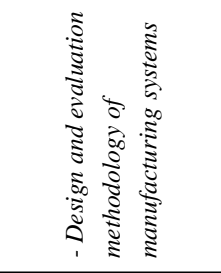 } & \multirow{2}{*}{$\begin{array}{l}\text { \& } \\
\text { इ } \\
\text { है }\end{array}$} & 1 & 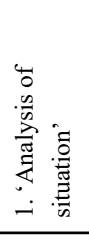 & 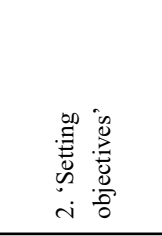 & 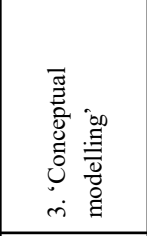 & 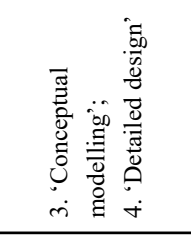 & 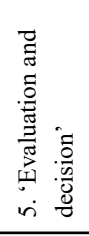 \\
\hline & & & & $>$ & $\odot$ & $\odot$ & $>$ & $>$ \\
\hline \multirow[t]{2}{*}{ 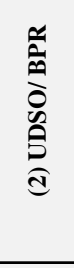 } & \multirow[t]{2}{*}{ 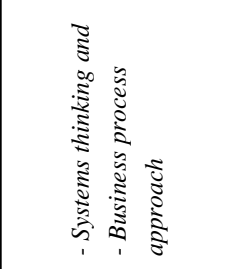 } & \multirow[t]{2}{*}{ 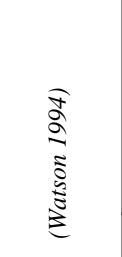 } & 1 & 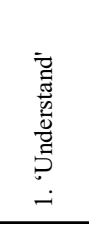 & 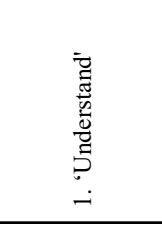 & 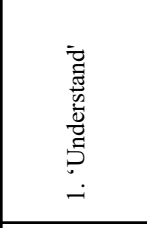 & 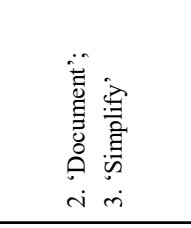 & 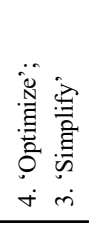 \\
\hline & & & & $>$ & $\odot$ & $>$ & $>$ & $\odot$ \\
\hline \multirow[t]{2}{*}{ 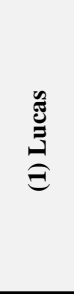 } & \multirow[t]{2}{*}{ 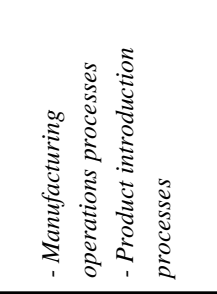 } & \multirow[t]{2}{*}{ 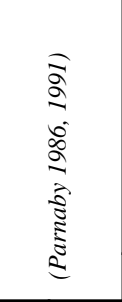 } & 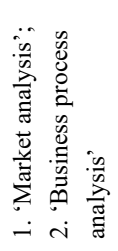 & 1 & & 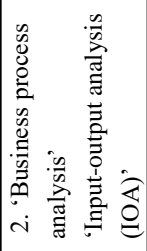 & 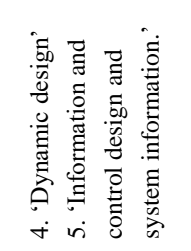 & 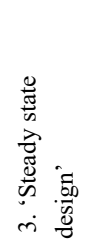 \\
\hline & & & $>$ & & & $>$ & $\odot$ & $\odot$ \\
\hline 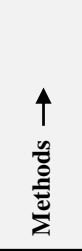 & 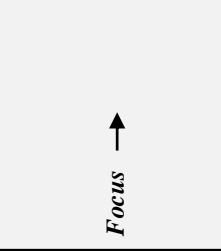 & 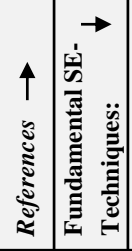 & 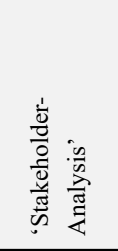 & 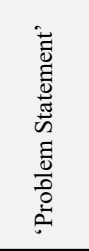 & 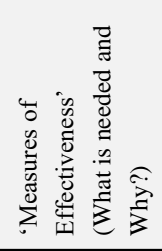 & 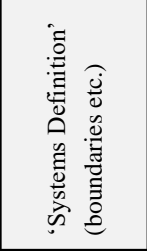 & 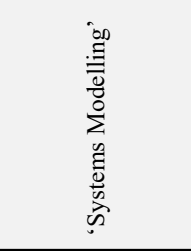 & 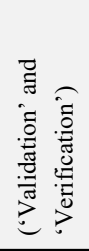 \\
\hline
\end{tabular}

